\section{EXTENSÃO DA AÇÃO DECLARATÓRIA}

\section{Galeno Lacerda}

Assistente de Processo Civil na Faculdade de $\mathrm{Di}$ reito de P. Alegre.

1 - Ensinam os autores que o exercício da ação declaratória está sujeito ao concurso dos seguintes requisitos:

a) incerteza quanto à existência ou inexistência da relação jurídica

b) possibilidade de o autor sofrer um dano, se a incerteza não fôr eliminada pela coisa julgada, e

c) aptidão da sentença declaratória para eliminar a incerteza e impedir o dano.

Nossos Tribunais, na prática, têm superestimado êstes requisitos, de tal sorte que se pode afirmar, sem receio de contestação, que grande parte das ações declaratórias terminam pela rejeição preliminar. As mais das vêzes, concluem os acórdãos "não ser caso da ação".

Em verdade, o problema da extensão da ação declaratória vem sendo enfrentado com angústia e avareza não apenas pela doutrina, mas mais ainda pela jurisprudência.

Enquanto aquela submete o interêsse de agir a condiç̃es de difícil apreciação, esta é tentada a considerar a declaratória sob o critério estreito de um procedimento especial, esquecida de que a declaração é função principal do processo.

Via de regra, as sentenças que rejeitam a ação na preliminar destoam das modernas concepções do direito processual, olvidam-se de que o processo existe para a realização da justiça mediante a solução ou prevenção da lide e que, assim, o cujdado exagerado da questões instrumentais compromete fundamentalmente aquela finalidade. A jurisdição se exaure de fundamentalmente aquela finapróprios objetivos e forma irustra, atraicoando a seus

Nunca será bastante Nunca será bastante o louvor à nova teoria das nulidades processuais, ao sadio relativismo que a domina, à clara noção de meio de fim que trouxe à atividade jurisdicional.

A facilidade em repudiar-se a declaratória, que ainda ensáia seus primeiros e tímidos passos no universo dos remédios processuais, não parece manter, assim, perfeita consonância com os princípios básicos do direito judiciário.

A culpa da incompreensão em que foi lançado êste tipo de ações cabe, porém, antes à doutrina que à jurisprudência. O's requisitos a que aquela o submeteu, pretendendo através dêles refletir traços próprios do instituto, não resistem a uma crítica mais detida.

2- Inicialmente, cumpre distinguir entre ação declaratória pròpriamente dita e função declaratória do processo.

Esta existe nos três tipos fundamentais de ação. É, mesmo, a função principal da jurisdição - a declaração do direito. Nas ações condenatórias, essa declaração é prévia à condenação. E, se a sentença aí proferida desestima a demanda, ela se torna puramente declaratória. Nas ações constitutivas, a sentença é por igual declaratória: limita-se, no fundo, a declarar o nascimento, a extinção ou a modificação da relação jurídica. E, nas ações pròpriamente declaratórias, ela se cinge a declarar a existência ou inexistência da relação.

Tôda ação é, pois, em princípio, de conteúdo declaratório, o que se evidencia se considerarmos que, distinguindo-se elas pela natureza do pedido, nêle é comum o elemento declaração, conforme se vê dêste esquema:

Ação condenatória $=$ declaração + condenação.

Ação constitutiva = declaração constitutiva.

Ação declaratória $=$ declaração pura, não constitutiva

Geram sentenças apenas declaratórias tôdas as ações pròpriamente declaratórias, tôdas as ações constitutivas e as condenatórias em que o pedido fôr rejeitado.

Sendo, portanto, a declaração o elemento comum a tôdas as ações e afirmando a lei positiva, no direito brasileiro, de acôrdo, aliás, com as concepções mais ortodoxas, que o interêsse do autor poderá limitar-se à declaração da existência ou inexistência da relação - claro está que, do ponto de vista lógico, a ação declaratória, de menor compreensão que as demais, possuidoras de notas que as singularizam (condenação ou constituição), terá necessàriamente maior extensão que aquelas.

Demonstra-nos, assim, a lógica, que o campo de exercício da ação declaratória, meio não só de definição como de prevenção da lide, é forçosamente mais vasto que o das ações condenatórias e constitutivas.

3 - Como justificar-se, pois, a série de condições restritivas opostas pela doutrina e acolhidas pela jurisprudência ao exercício dêste remédio processual? 

Por que motivo o interêsse legítimo, na ação declaratória, há
de ser de mais difícil verificação, sujeito reclamados pelos autores quando, sujeito a requisitos próprios, não

Como conciliar estas exigências tratam das outras ações?

o campo de aplicação da declaratóriae, a primeira vista, angustiam levam a lógica num exame ser conclusões a que nos

$\mathrm{Na}$ verdade,

ação declaratória - e neste póes não são próprias e exclusivas da doutrina. Os requisitos por ponto reside o equívoco principal da comuns a tôdas as ações, ou dizem propostos para o instituto, ou são de ação declaratória, a preventivem respeito sòmente a um dos tipos às demais, porque transcende a

Examinemos, porém em as condições comuns que as legimam.

txaminemos, porém, em particular, cada um dêstes requisitos.

4 - Exige-se, inicialmente, incerteza quanto à existência inexistência da relação jurídica.

Que incerteza será esta? Subjetiva ou objetiva? Sendo ela condição para o interêsse de agir, será um dado do sujeito ou do
objeto?

A rigor, deveria sê-lo do sujeito, pois que a pesquisa do interêsse legítimo mergulha fundo no problema das intenç̃es do autor blema eminentemente subjetivo.

Subor

ação declaratória, à verifim, a ocorrência do interêsse legítimo, na autor quanto ̀̀ à

E enveredariamosia ou inexistência da relação.

jetivismos, acadêmico e anti-cia um campo perigosíssimo de subincerteza subjetiva, via anti-científico, além de irreal, pois que a parte das vêzes, nom subjetiva de seu direito sentença contrária fá-lo perder a certeza$$
\text { Fugind à dificuldade, }
$$

incertezando à dificuldade, apressam-se os autores a afirmar que a claratória é objetiva não legitimar-se o interêsse do autor na dearária é objetiva, não subjetiva.

Mas, que é a incerteza objetiva?

Colocando a questão em têriva?

objetiva aquela que não depende de positivos, entende-se por certeza do sujeito, isto é, a não depende de nenhuma circunstância pessoal

O interêsse a evidência da coisa.

à não evidência quanto à existência tória, estaria subordinado, assim, incerteza in rem, à incerteza ontoló ou inexistência da relação, à

Dentro do dicerteza ontológica.

quando, em que momento ; tência ou não da relação jurídica atinge a certeza ontológica da exisda autoridade e eficácia da coisa julgancial? Não é sòmente através
Enquanto a sentença de mérito não transitar em julgado, reina dentro da ação uma incerteza objetiva quanto à existência ou inexistệncia da relação.

Este estado de incerteza objetiva é comum a tôdas as ações. Encontramo-lo não apenas na declaratória, mas igualmente na condenatória e na constitutiva.

O interêsse do autor, nestas, como naquela, se apresenta sob um clima de incerteza objetiva quanto à existência do direito alegado. Esta incerteza, que ocorre em tôda ação, só se desfaz pela coisa julgada material.

O primeiro requisito exigido pela doutrina para o exercício da ação declaratória - a incerteza objetiva quanto à existência ou inexistência da relação jurídica - é, assim, comum a tôdas as ações.

5 - Poder-se-ia objetar que essa incerteza que se faz presente em tôdas as acões é a que ocorre dentro do processo, sob a forma de espectativa quanto ao resultado da sentença, ao passo que, na ação declaratória, se exige que ela exista antes do processo, sem qualquer referência à futura sentença. A primeira diria com o plano ontológico formal, a segunda com o material.

$\mathrm{O}$ argumento não procede, por isto que a espectativa que se gera no curso da ação quanto ao resultado da sentença nada mais é que a projeção dentro do processo da incerteza objetiva, material, que existe anteriormente à demanda.

Se o estado de incerteza prévia fôsse próprio e exclusivo da declaratória, seria interessante indagar qual a certeza objetiva que poderá haver antes das acões condenatórias ou constitutivas? Evidentemente, nenhuma. Se nestas houvesse a certeza prévia quanto à existência do direito alegado pelo autor, não teriamos possibilidade de demanda infundada.

Tomemos como exemplo, capaz de gerar o mais alto grau de certeza sôbre a existência da relação, o caso da ação executiva cambiária, tìpicamente condenatória.

Ainda aqui não teriamos certeza absoluta antes ou no curso da ação. Basta que se admita a possibilidade de defesa causal ou extintiva do pedido, para que se caia no estado de incerteza objetiva.

E, já que se trata de ação executiva cambiária, por que não admitir-se também ação declaratória para a decretação da existência ou não da obrigação? O título, que se presume líquido e certo, não comportaria a ação?

Evidentemente, sim. Se se admitem, na condenatória, defesas causais ou extintivas do pedido, a declaratória é sempre possível. Como argumento de ordem legal, ainda, bastaria considerar que o Código de Processo, sem qualquer restrição, afirma que o interêsse do autor pode limitar-se à simples declaração da existência ou ine- 
xistência da relação, interêsse que se justifica, portanto, mesmo quandô do litígio se possa gerar ação cambiária.

Como se vê, ainda nos casos em que se presuma um alto grate de certeza quanto à existência da relação, o que se verifica é que, em verdade, a incerteza objetiva existe, mesmo nas açóes fundamentalmente condenatórias.

Esta incerteza objetiva, via de regra, é causa do litígio, da controvérsia, da qual nasce a ação.

Existe, portanto, em tese, sempre que houver ação, seja ela qual fôr.

6 - Generaliza-se, desta forma, o primeiro requisito que a doutrina vislumbrara como próprio da ação declaratória.

Vejamos se os demais comportam a pretendida exclusividade.

Como segunda condição capaz de legitimar o interêsse do autor na declaratória, se requer a possibilidade de vir êle a sofrer um dano se a incerteza não fôr eliminada pela coisa julgada.

A condição, em parte, está prejudicada pelos argumentos anteriores, em que se demonstra que o estado de incerteza é comum tôdas as ações.

Tendo a incerteza gerado o conflito, dêle nasceu evidentemente, pelo menos do ponto de vista subjetivo, o dano para o autor. Dano agudo e gritante, nas ações condenatórias, em que se pede reparacão; dano latente ou também agudo, nas acões que pede reparação reclama a modificãão a

A existência do

Mas, não haver Mas, não haverá um nota peculiar à declaratória no requisito que vimos analisando? Há, com efeito, mas para determinado tipo
de declaratória.

É que a ação declaratória, como vimos, é de maior extensão que as demais, pois que pode ser proposta não só quando o dano já se verificou, mas ainda quando existe a sua simples possibilidade.

Neste caso, justifica-se, para o exercício da ação declaratória preventiva, o requisito da possibilidade do dano. Note-se, porém, que êste requisito não importa em restrição ao uso da ação comparativamente ao das demais. E que êle se refere a um tipo inexistente nestas últimas - a ação preventiva. A possibilidade inexistente nada mais é que a concretização do próprio interêsse legítimo de agir.

Esquematizando, diriamos que a ação declaratória pode ser usada em todos os casos de condenatória. Não diriamos que ela pode sê-lo. em todos os de constitutivas, mas que ela é declaratória, lato sensu. em todos êles. E que, além disto, pode revestir-se de modalidadé ignorada das outras - a preventiva.

Nesta última hipótese terá por condição a possibilidade de dano, como expressão peculiar no caso do interêsse de agir.
7 - O terceiro requisito posto pela doutrina é que a sentença declaratória seja apta para eliminar a incerteza a impedir o dano.

Que ela seja apta para eliminar a incerteza - não há nisto nenhuma propriedade da declaratória. Tôdas as sentenças de mérito, passadas em julgado, eliminam a incerteza objetiva que existe em tôdas as ações.

Que ela seja apta para impedir o dano - há neste requisito o perigo de uma contradição flagrante. Como pode a declaratória impedir o dano, se ela não tem coercibilidade sôbre as partes, se vale apenas como preceito? Não seria esta condição a negação da própria declaratória?

Sua eficácia é antes moral que material.

Seria de reconhecer-lhe a virtude impeditiva se déssemos valor absoluto à sua autoridade moral, se considerássemos o dano apenas em seu aspecto ético, ou naqueles poucos casos em que êle pudesse ser evitado, por exemplo, pelo registro público ou sua anúlação, hipóteses em que se admite execução da sentença declaratória.

Mas, eficácia impeditiva ou restauradora do dano têm-na, em grau mais elevado, as sentenças condenatórias e constitutivas.

Donde concluir-se, uma vez mais, pela irrelevância do terceiro requisito com que a doutrina pretende delimitar o uso da declaratória.

8 - Demonstrada, desta forma, a inconsistência dos argumentos. restritivos, no que concerne ao interêsse legítimo para o exercício da ação declaratória, fica evidenciada a exatidão da análise anterior em que se verificou, em têrmos de lógica formal, que a extensão dêste tipo de ações é maior que a dos demais.

$\mathrm{O}$ argumento legal conforta a tese.

Se a lei concede que o interêsse do autor possa limitar-se à declaração da existência ou inexistência da relação jurídica, é porque podem gerar declaratórias todos os casos que dariam margem a ações condenatórias.

Não diriamos o mesmo das ações constitutivas porque elas já são, de si, declaratórias em sentido lato. Nelas, o interêsse do autor não se limita à declaração da existência ou inexistência da relação - êle consiste, precisamente, na declaração de existência de uma nova relação, de modificação na atual ou de sua extinção. $O$ fenômeno declaratório é o mesmo.

A ação declaratória possui, assim, extensão mais vasta que as demais, pois se apresenta, em sentido próprio ou lato, em todos os casos em que estas podem ser exercidas e, além disto, ainda naqueles em que o conflito não se manifestou, em que se a usa de forma preventiva, outorgando às partes um título que valha como preceito, como norma, para o caso concreto. 
Mas, por que motivo pode o interêsse do autor limitar-se à declaração da existência ou inexistência da relação, circunstância que o legitima para a declaratória nos mesmos casos da condenatória?

A razão decorre de princípios fundamentais do direito processual civil.

Se, nêle, a incoação é da parte; se, como conseqüência, se veda ao juiz sentenciar ultra-petita; se a parte é livre de fazer valer ou não em juízo o seu direito; se ela tem o poder de movimentar com o seu pedido tôda a máquina jurisdicional e de delimitar a atividade desta nas lindes traçadas na inicial; em suma, se a ação é um direito potestativo - então, o autor tem o poder de desprezar a condenação e exigir a prestação jurisdicional ùnicamente para a declaração $\mathrm{da}$ existência ou inexistência da relação jurídica.

Razões óbvias, de ordem moral e até jurídica, legitimam tal procedimento, e a êle o Código dá guarida expressa no parágrafo único do artigo $2 .^{\circ}$

Mais não será preciso para demonstrar-se o vastíssimo alcance da ação declaratória, e o motivo por que nela encontrou o gênio prático dos norte-americanos um dos mais salutares remédios judiciais.

Vê-se, agora, como o problema do interêsse nesta ação é simples, como êle não tem nada que o singularize em relação às demais e como tem sido mal posto pela doutrina com desastrosa repercussão sôbre a jurisprudência, criando-se assim um clima de incompreensão para um remédio fadado por sua natureza à mais larga aplicação na prática processual.

9 - Como conseqüência a latere da análise feita, seria curioso assinalar que não se justifica a divisão tripartida das ações. Uma vez que as constitutivas se reduzem, em última instância, às declaratórias - só seria aceitável, no fundo, uma divisão bipartida, de acôrdo com o esquema abaixo:

Ações $\left\{\begin{array}{c}\text { condenatórias } \\ \text { declaratórias } \\ \text { lato senst }\end{array} \quad\left\{\begin{array}{c}\text { constitutivas } \\ \text { declaratórias, pela renúncia } \\ \text { processual à condenação } \\ \text { declaratórias preventivas }\end{array}\right.\right.$

Este esquema evidencia a importância fundamental da ação declaratória.

E tempo de abrirmos os olhos para os horizontes que ela possui, e de os aceitarmos com a sua amplidão, saindo, enfim, de um empirismo estreito e negativista, que se aferra a condições de formulação esdrúxula, cuja singularidade é puramente nominal, próprias como são a tôdas as ações, ou então incompatíveis com o instituto que desejam asfixiar sob sua sujeição.

Reconheçamos que ela vem dar novo sentido à atividade jurisdicional, facilitando a consecucão de seus objetivos, pela prevenção dos litígios e pela definição do direito sempre que solicitada pela parte. Nela a justiça se torna mais simples, mais acessível, mais despida de formalismos.

$A$ ação declaratória, em verdade, espera compreensão.

\section{RELATÓRIO E PARECER}

\section{Relator: VICENTE MARQUES SANTIAGO}

O dr. Galeno Lacerda, assistente da Cadeira de Direito Judiciário Civil desta Faculdade, enfrenta, em sua brilhante tese, relativa à "Extensão da ação declaratória", um dos mais sugestivos e controvertidos temas suscitados pelo processo moderno.

Estuda com mérito indiscutivel os diversos aspectos que a doutrina oferece, para a sua caracterização e, pelo confronto dos respetivos requisitos com os exigidos nas ações de condenação, conclui que assim se identificam ambos os remédios processuais, sob êsse aspecto, para se diferençarem apenas pelos efeitos da sentença.

Entretanto - é o jovem jurista quem o diz - nossos tribunais, na prática, têm superestimado êstes requisitos, de sorte a se poder afirmar que grande parte das ações declaratórias termina pela rejeição preliminar, o que se deve à angústia e avareza com que a doutrina, e mais ainda a jurisprudência, as vêm enfrentando.

Partindo do princípio de que só à parte cabe a incoação no processo civil, condena, coerentemente com as premissas estabelecidas, a incompreensão a que foi lançado êsse tipo de ação, cuja admissibilidade deve resultar do respeito às três condicões clássicas para o êxito da ação. Conclui pela extensão da ação declaratória aos casos em que se permita o uso da executória.

Cumpre se destaque, desde logo, a interessante colaboração representada pela tese, ao estudo dêsse gênero de ação que, sendo de uso recente em nosso País, não tem as respetivas lindes suficientemente caracterizadas. E, assim considerando, não hesito em afirmar a originalidade de seu esfôrço e o brilho de sua realização.

Não nos convence, entretanto, o autor, da necessidade, nem mesmo conveniência de por tal forma estender o campo de aplicação da ação declaratória, cuja finalidade bem se situa na obtenção da certeza em tôrno de um interêsse desprovido, momentâneamente, de outra forma de proteção mais específica. 
A extensão que lhe pretende dar a tese ultrapassa o objetivo que presidiu à sua origem. Nem se justifica a invasão que por ela se opera no campo das ações de condenação, cuja finalidade, por mais completa, mais se coaduna com os princípios que regem o moderno processo civil, de afirmar a vigência da lei e sua aplicacão ao caso concreto, como meio de defesa da sociedade e de proteção do direito privado subjetivo. Sempre, porém, com o mínimo de perturbação social, de sorte a que não venha a ação reparadora a constituir razão de maior alarme e desprestígio que o próprio ato que tende a reprimir

Por que admitir-se o uso da ação declaratória quando já exigível. a obrigação, objeto da dúvida, quando isso importará na duplicação de processo?

Essa a razão por que resistem os tribunais em assim ampliar o uso da ação declaratória.

Pensamos, com o Tribunal de Justiça de Minas Gerais, que a ação declaratória tem por fím exclusivo resguardar as relações jurídicas que, por falta de exigibilidade atual, possam tornar-se incertás, sofrer uma redução de importância cu perder a vitalidade. Constitui, pois, mero remédio preventivo, desprovido de execução compulsória. Ou, como afirma Hugo Alsina, quando exista um estado de incerteza sôbre a existência ou interpretação de uma relação de direito, capaz de causar prejuízo e desde que não haja outro recurso legal.

Eis porque concordamos integralmente com os dispositivos propostos pelo Ministro Costa Manso, quando da elaboração do Código de Processo Paulista, nos quais, com a devida precisão, se fixam os casos em que pode a ação declaratória ser proposta, bem como se propõem soluções para situações resultantes da propositura de mais de uma ação, como pode ocorrer fàcilmente, uma de condenação, por uma das partes, e outra declaratória, pela outra.

Em conclusão, rénovo o louvor inicial à tese apresentada, embora não lhe subscreva as conclusões, como sumàriamente ficou exposto.

\section{CARATER CIVIL DA PRESCRIÇÃO DAS DIVIDAS PÚBLICAS PASSIVAS DE ORIGEM FISCAL}

\section{Galeno Lacerda}

Assistente de Processo Civil na Faculdade de Direito de P. Alegre. Auditor do Tribunal de Contas do Estado.

1 - A questão da prescrição das dívidas públicas passivas de origem fiscal é bastante controvertida. $O$ assunto mais se aguça em relação às dívidas passivas dos Estados e Municípios. Sendo, entre nós, privativa a competência da União para legislar sôbre direito civil, indaga-se se podem as outras pessoas de direito público mterno fixar prazos prescricionais para a reclamação de cobrança fiscal indevida. Essa prescrição será matéria de direito civil ou de direito financeiro?

Duas correntes - a publicista e a civilista - chocam-se na solução da tese.

Adepto da primeira, nosso ilustre colega ALVARO BAPTISTA DE MAGALHÃES, em sua magnífica introđução ao "Ante-Projeto de Código Tributário e Fiscal para os Municípios", entende que o direito financeiro, sendo de ordem pública, possui disciplina própria, distinta da que concerne ao direito civil.

Considerando que o Código Civil regula "os direitos e obrigaçoes de ordem privada" (art. $1 .^{\circ}$ ), declara: "É bem de ver que, lançando impostos, não age o Estado dentro da esfera do direito civil. O imposto é uma obrigação compulsória, inteiramente alheia ao direito privado. Parece-nos, assim, que não se podem aplicar às relaçóes daí decorrentes as determinações da lei civil" (op. cit., pag. 30).

E, mais adiante: "Em realidade, como o direito financeiro é restrito e privativo, a capacidade para instituir a prescrição pertence à entidade pública que fôr competente para decretar o impôsto" (pag. 32)

Invoca em favor de seu ponto de vista as opiniões respeitáveis de AMILCAR DE CASTRO, VIOTTI DE MAGALHÃES, CASTRO MAGALHÃES, ANDRADE FIGUEIRA e BARBOSA 'CAMPOS. 